\title{
Learning style preferences of undergraduate paramedic students: A pilot study
}

\author{
Brett Williams ${ }^{1}$, Ted Brown ${ }^{2}$, Christian Winship ${ }^{1}$ \\ 1. Department of Community Emergency Health and Paramedic Practice, Monash University, Australia. 2. Occupational \\ Therapy, Monash University, Australia.
}

Correspondence: Brett Williams. Address: PO BOX 527 Monash University, Victoria, Australia, 3199. Telephone: 61399-044-283. Email: brett.williams@monash.edu.

Received: January 30, 2012

Accepted: March 1, 2012

Published: January 1, 2013

DOI : $10.5430 /$ jnep.v3n1p51

URL: http://dx.doi.org/10.5430/jnep.v3n1p51

\begin{abstract}
Background: It has been identified that health science students, and in particular, undergraduate paramedic students may have distinct learning needs. By educators being conscious of the unique learning styles of undergraduate paramedic students they will have the ability to organise learning activities for paramedic students that will optimise their educational experiences. The purpose of this study was to investigate the learning style preferences of undergraduate paramedic students.

Methods: A cross-sectional study using a paper-based version of the Kolb Learning Style Inventory (K-LSI) was administered to a cohort of students enrolled in an undergraduate paramedic degree at an Australian university. There were 170 paramedic students eligible for inclusion in the study.

Results: There were 57 students (response rate of 33.5\%) that participated in the study, of which $70 \%(n=40)$ were female. The results indicated that undergraduate paramedic students have a preference for two learning styles: the Diverger style of learning (31\%) and the Accommodator style of learning (26.5\%).

Conclusions: It is recommended that educators take into consideration the learning style preferences of undergraduate paramedic students when developing curriculum and evaluating teaching approaches, especially when planning, implementing and evaluating education initiatives in order to create an effective learning environment for their students.
\end{abstract}

\section{Key words}

Learning Styles, Kolb learning style inventory, Paramedic, Undergraduates

\section{I ntroduction}

Considerable attention has been given to the exploration of learning styles, particularly the learning styles of health science students ${ }^{[1]}$. Increasing responsibility is being placed on university educators to ensure that undergraduate students have been exposed to content defined by external curricula, industry, and college demands (i.e. Paramedics Australasia in Australia, College of Paramedics in the United Kingdom (UK), and Paramedic Association of Canada) and to provide evidence that teaching has been effective and that learning has taken place ${ }^{[2]}$. This emphasis is particularly important to paramedic educators in the Higher Education sector, as the discipline is still relatively new to university-based education, 
with many undergraduate programs around the world yet to be formally accredited, highlighting that many curricular renewal issues will need to be addressed.

In an effort to understand the learning needs of individual learners, educational psychologists have proposed the existence of cognitive learning styles for many decades ${ }^{[3]}$. The overall goal of this study is to investigate the learning styles of undergraduate paramedic students in traditional classroom settings and to determine if teaching strategies align with undergraduate paramedic students' learning styles. While the learning styles of other health-related disciplines (such as nursing and medical students) have been investigated, relatively little empirical work has been completed related to paramedic students. New knowledge in this area will have direct benefits for paramedic educators and academics around the world.

\subsection{Kolb's experience learning theory}

Kolb has long been considered to be pre-eminent in the field of learning styles, with the tried and tested widely referred to Kolb’s Experience Learning Theory and Kolb’s Learning Style Inventory ${ }^{[4]}$. Kolb’s Learning Experience Theory was chosen due to two distinct features: 1) learning styles are both flexible and stable, and 2) Kolb is based on the theory of experiential learning which incorporates growth and development ${ }^{[5]}$. Both of these features are central to undergraduate university education. Additional reasons for choosing Kolb's Learning Experience Theory included a wide body of research accumulated over 30 years ${ }^{[6]}$ and its use in investigation with other health science students including nursing, allied health, physiotherapy, and pharmacy ${ }^{[1,7-10]}$. The following studies highlight the work being undertaken in the health sciences, underscore work undertaken in various health care professions for example, such as nursing students that have been examined by King, and Smith ${ }^{[7,8]}$, allied health students have been examined by Hauer et al ${ }^{[9]}$, physical therapy students have been studied by Bowman et al ${ }^{[10]}$, and a large interdisciplinary study on all health science students at a Australian university by Zoghi et al. ${ }^{[1]}$.

The basis for the use of Kolb's Learning Experience Theory with health science students is that students' learning evolves as they steer navigate through their individual learning experiences. As students progress through both their academic learning and practical skills training, they must also become accustomed to the concept of being health care professionals. As they navigate the continuum of novice to expert a number different of learning environments are used, for example, through clinical placement and clinical simulation laboratories ${ }^{[1]}$. As mentioned previously, Kolb's learning theory can accommodate for the potential growth experiential learning and students' learning styles as they progress through varying learning environments ${ }^{[8]}$. This is particularly relevant to undergraduate paramedic education as multiple learning sites are often used throughout their coursework program to simulate real life clinical problems and complications.

Kolb identified four distinct learning styles that can be placed on a model with two axes (see Figure 1). The horizontal axis is referred to as the processing continuum demonstrating a preference for performing tasks on one end (Active experimentation or $\mathrm{AE}$ ) and for observing at the other end of the scale (Reflective observation or RO) ${ }^{[4]}$. The vertical axis is referred to as the perception continuum, indicating a preferred learning style based upon feeling at one end (Concrete experience or $\mathrm{CE}$ ) and thinking at the other end (Abstract conceptualisation or AC). The four quadrants are formed by the intersection of the two axes representing four learning styles that are derived from a combination of two preferred learning abilities. These four learning styles are the Diverger (combination of CE and RO), Assimilator (combination of AC and $\mathrm{RO}$ ), Converger (combination of AC and AE), and Accommodator (combination of CE and AE) styles ${ }^{[4]}$.

Based upon Kolb's theory, learning is a cyclic process that involves four different modes of learning (see Figure 1); abstract conceptualisation (AC), active experimentation (AE), concrete experience (CE), and reflective observation (RO) ${ }^{[5]}$. In the process of education of health science students, abstract conceptualisation (AC) represents theoretical "thinking" processes. This then results in with the result being active experimentation (AE), where students actually use the knowledge that they have gained to formulate a theory on completion of a task or "doing” phase. The outcome of a task, whether positive or negative, is concrete experience (CE) or "experience" phase of learning. Post concrete 
experience (CE) is reflective observation (RO) where students reflect on what worked and perhaps did not work, also known as "reflecting". This cycle is a continuous, reoccurring process, with students frequently making the transition from phase to phase as directed by their learning needs ${ }^{[8]}$. An example of Kolb's theory using health care students could be the following scenario. A student is presented with a clinical problem where the student identifies a patient in a wide- complex tachycardia (AC) and chooses to administer Amiodarone to treat this abnormality (AE). The student administers the drug to the patient (CE) and as a result the tachycardia is terminated. The student then reflects that Amiodarone was an appropriate choice of drug for this clinical problem (RO). Similar types of examples would be played-out in many paramedic and health-related university programs around the world.

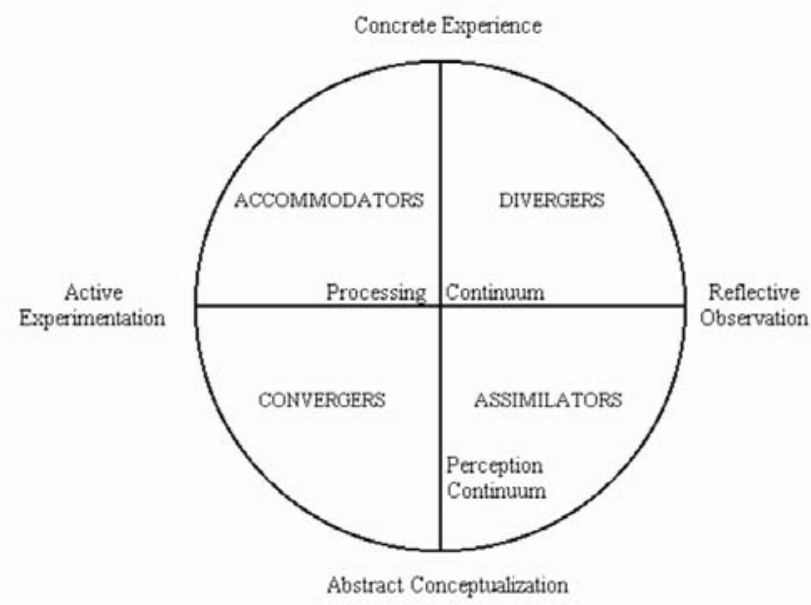

Kolb's Learning Styles

Figure 1. Kolb Learning Styles

According to Kolb's learning styles definition of the different learning styles, the diverger's greatest strength lies in his or her creativity and imaginative ability. Students employing under this learning style tend to be best at viewing situations from a number of different perspectives. These learners tend to be interested in arts and to have humanities or liberal art backgrounds. The converger's greatest strength is an ability to apply practical ideas to problems and perform at their optimal best when there is only one correct answer. Learners whose learning style falls in this quadrant are relatively unemotional, and prefer to deal with things rather than people. They often choose to specialise in physical science, engineering and computer science ${ }^{[1]}$.

Assimilators are very competent at understanding a wide variety of information and putting it into concise, logical order and excel at creating theories. Learners who fall under the category of assimilators tend to do extremely well at basic mathematics and science, rather than applied science, and often choose careers involving research and planning. The final learning style is the Accommodator, which is characterised by primarily hands-on experiences and enjoyment of becoming involved in new and challenging experiences. Learners who prefer this learning style often excel in practical fields such as business and education and tend to choose careers in "action-orientated" jobs such as marketing, teaching, or nursing ${ }^{[7]}$.

Kolb's learning style theory has been tested and developed in the form of a standardized self-report questionnaire known as the Kolb’s Learning Style Inventory (K-LSI) ${ }^{[4]}$. The K-LSI is a self-descriptive, self-scoring scale designed to help individual learners identify their optimal learning styles and to better understand the learning cycle that is described by Kolb $^{[5]}$. 


\subsection{Assessing the learning styles of health care professionals}

The K-LSI is one of the most frequently used scales for determining the learning styles of health care professionals. There have been several studies, mainly in the United States, attempting to link a particular learning style with a selected health care discipline. In a study conducted by Cavanagh et al ${ }^{[11]}$ on 192 registered general nursing students, before they had any contact with lecturing staff, revealed that 53.7\% of students had an Accommodator learning style, while 46.3\% were Reflective (Assimilator plus Converger score) ${ }^{[11]}$. The findings from Cavanagh et al. ${ }^{\text {[11] }}$ support the earlier findings of King ${ }^{[9]}$, who found that nursing students tended to be either Accommodators or Divergers. Moreover, in a study conducted by Bowman et al ${ }^{[7]}$, it was noted that male physical therapy students preferred the Converger style of learning, compared to female physical therapy students who favoured the Assimilator learning style. The results found by Zoghi, et al ${ }^{[1]}$ indicated that the favoured learning style preference of Australian health science students was the Converger style, with the learning styles of Accommodator and Diverger least favoured ${ }^{[1]}$. The findings of both King ${ }^{\text {[9] }}$ and Cavanagh ${ }^{[11]}$ are consistent with Kolb's theory that people associated with human-orientated professions are more likely to adopt concrete learning styles and are more person-orientated.

It is evident that the current evidence base shows that there is a variance in learning style preferences between different health care disciplines, and even within health care disciplines. This indicates that educators need to cater for a spectrum of different learning styles, and not towards a single learning style. It was noted that there is a lack of research that has included undergraduate paramedic students.

The linking of teaching methods to the learning styles of health science students, and in particular undergraduate paramedic students, would promote optimal learning conditions for students in educational contexts, and at the very least provide important information for curriculum design and renewal. Therefore, the aim of this study was to determine the learning style preferences of undergraduate paramedic students at a single Australian University.

\section{Subjects and methods}

\subsection{Design}

A non-experimental prospective cross-sectional survey study design was used, which is commonly used in pilot studies ${ }^{[12]}$.

\subsection{Participants}

All students enrolled during 2009 in the Bachelor of Emergency Health (BEH) degree at Monash University were potential respondents $(n=170)$. Inclusion criteria for participants were enrolment at Monash University in the BEH on a full- or part-time basis during 2009, and consenting to participate.

\subsection{I nstrumentation}

Participants completed a self-report questionnaire which was divided into two sections. The first section asked for demographic information (20 questions) including year level of the BEH, type of enrollment, gender, age, secondary school completion or equivalent, any previous tertiary education before enrolling in the current undergraduate paramedic degree, and ethnicity.

In the second section, the K-LSI ${ }^{[4]}$ was used to assess the learning mode and style of students enrolled in the BEH. The K-LSI includes 12 questions that describe various learning contexts. Each question has four responses, and participants are asked to rank these from the response that best describes their learning style ${ }^{[13]}$ to the response which least describes them ${ }^{[14]}$. The value for each response (ranked from 1-4) is placed into one of four equations; CE, RO, AC and or AE. A total for each equation is then derived, which equates to a numerical value for each of the four learning modes: $\mathrm{CE}$, RO, 
AC, and AE. The value obtained for CE is then subtracted from the value obtained for AC; this yields the y-coordinate. The value derived for RO is subtracted from AE to yield the $\mathrm{x}$-coordinate. The $\mathrm{x}$ and $\mathrm{y}$ values are then plotted on Kolb's Learning Style Grid, resulting in a preferred learning style: Diverger (CE and RO), Assimilator (AC and RO), Converger (AC and $\mathrm{AE}$ ), and Accommodator (CE and $\mathrm{AE})^{[15]}$.

The psychometric properties of the K-LSI have been established. This tool is reliable, with Cronbach's alpha coefficient scores for internal consistency ranging from 0.43 up to 0.79 and the test-retest reliability for the four learning styles ranging from 0.91 to $0.97^{[16]}$. Its validity has been supported in many cross cultural studies in many countries ${ }^{[17]}$.

\subsection{Procedures}

Approval from the Monash University Committee on Ethics in Research on Humans was obtained before commencement of the project. Participants were given a brief overview of the project, along with the distribution of the self-report questionnaire during a scheduled class and were asked to participate on a voluntary basis after the completion of a lecture, by a non-faculty member of staff.

\subsection{Data analysis}

The Statistical Package for Social Sciences (SPSS, version 17.0) was used for data entry, storage, retrieval, and the generation of descriptive statistics ${ }^{[17]}$ which were used to summarise and the four K-LSI scales: AC, CE, AE, and RO. Group mean scores for AC and CE were then subtracted to obtain a y-axis coordinate; scores for AE and RO were used to obtain the $\mathrm{x}$-axis coordinate.

\section{Results}

\subsection{Response rate demographics}

In the present study, the K-LSI was administered to 57 students enrolled in the BEH at Monash University. A total of 57 questionnaires were returned their questionnaires, which accounted for a 33.5\% response rate. The distribution of the demographic data is reported in Table 1 . The final sample contained more females $(n=40)$ than males $(n=17)$. An important phenomenon to emerge in the results was the uneven distribution of males; however this represents the current enrollment status in the BEH course where the majority of student enrollments are female. Over $47 \%$ of students who completed the questionnaire were between 20 and 24 years of age. Only 30\% of respondents entered the BEH directly from high school, while $70 \%$ of students were from mature age entry or lateral transfer from health-related programs. Over half $(56 \%)$ of students that responded were in 2 nd year $(n=32)$. Caucasian ethnicity represented $93 \%(n=53)$ of all respondents were Caucasian in ethnicity, which appears consistent with previous enrollments, with $95 \%$ of students being enrolled full-time ( $\mathrm{n}=54)$, and only $5 \%$ being enrolled part-time (see Table 1$)$.

Table 1. Demographic variables $(\mathrm{N}=57)$

\begin{tabular}{lll}
\hline & Number & Percent \\
\hline Age & & \\
$15-19$ years & 13 & 22.8 \\
$20-24$ years & 27 & 47.4 \\
$25-29$ years & 10 & 17.5 \\
$30-34$ years & 2 & 3.5 \\
$35-39$ years & 4 & 7.0 \\
$40-44$ years & 1 & 1.8 \\
Total & 57 & 100 \\
\hline
\end{tabular}

(Table 1 continued on page 56) 
Table 1. (continued)

\begin{tabular}{lll}
\hline & Number & Percent \\
\hline Gender & & \\
Female & 40 & 70.2 \\
Male & 17 & 29.8 \\
Total & 57 & 100 \\
Year Level & & \\
$1^{\text {st }}$ year & 12 & 21.1 \\
$2^{\text {nd }}$ year & 32 & 56.1 \\
$3^{\text {rd }}$ year & 12 & 21.1 \\
Total & 56 & 100 \\
Ethnicity & & \\
Caucasian & 53 & 93.0 \\
Asian & 3 & 5.3 \\
Indian & 1 & 1.8 \\
Total & 57 & 100 \\
Entry direct from High School & & \\
Yes & 17 & 29.8 \\
No & 40 & 70.2 \\
Total & 57 & 100 \\
\hline
\end{tabular}

\subsection{K-LSI scores}

The distribution of students' learning style preferences of undergraduate paramedic students is reported in Table 2. Diverger was the most preferred learning style 31.5\% $(n=18)$ followed by Accommodator $26.3 \%(n=15)$. The least preferred learning style was Converger 19.2\% $(\mathrm{n}=11)$. Undergraduate paramedic students showed a preference for abstract conceptualisation (AC) which obtained the highest mean score, followed by reflective observation (RO) and concrete experience (CE) which obtained the same mean score. Mean scores for AC and CE were subtracted to obtain a y-axis coordinate; scores for AE (active experimentation) and RO were used to obtain the x-axis coordinate (see Table 2). The resulting $\mathrm{x}$ and $\mathrm{y}$ coordinates were then transposed onto Kolb's Learning Style Grid ${ }^{[4]}$ to determine the preferred learning style of undergraduate paramedic students. The breakdown of students' learning style preferences of undergraduate paramedic students is reported in Table 2.

Table 2. Distribution of Kolb’s four learning style preferences among students $(\mathrm{N}=57)$

\begin{tabular}{lllll}
\hline & Accommodator & Diverger & Assimilator & Converger \\
\hline $\mathrm{n}$ & 15 & 18 & 13 & 11 \\
$\%$ & 26.3 & 31.5 & 22.8 & 19.2 \\
\hline
\end{tabular}

\section{Discussion}

In this present study, the K-LSI was used to examine the learning style preferences of undergraduate paramedic students from a large Australian university. The results demonstrated that there is a wide range of learning style preferences among undergraduate paramedic students, with a relatively evenly spread learning style preference across all four learning styles, although two learning styles were more prominent. The Diverger style being was the most commonly preferred learning style by undergraduate paramedic students (31.5\% [n=18] of participants). Divergers are characterised by their ability to be creative and imaginative ability. A person who prefers this learning style excels in the ability to view concrete situations 
from many perspectives and generate many ideas such as in "brainstorming" sessions ${ }^{[1]}$. Students who prefer the Diverger style of learning are most comfortable in watching rather than doing, tending to gather information about the situation and using their imagination to solve problems. The students who prefer the Diverger style of learning are interested in people; and are imaginative and emotional, and like to tend to gather information and use their imagination to solve problems. This suggests that undergraduate paramedic students prefer to work in groups and to listen with an open mind and receive personalised feedback. Therefore learning activities could be tailored to include these dimensions in order to optimise the potential learning through means such as the provision of personal feedback by peers and or faculty staff. This is not to suggest that the other styles of learning should be ignored or neglected such as Assimilator, Converger and Accommodator as shown in Table 2. These findings also raise interesting questions surrounding whether learning styles have changed in paramedic education based on generational differences. In other words, what differences, perceptions or expectations do new students bring, and therefore, what impact does this have on their learning, and the approaches needed by educators.

The other learning style preferred by undergraduate paramedic students was an Accommodator style (26.3\%, $\mathrm{n}=15$ ). Accommodators are characterised as being 'hands on' learners that rely upon intuition rather than logic when dealing with tasks ${ }^{[1]}$. Accommodators are attracted to new challenges and experiences, and prefer to take a practical, experimental approach to completing tasks. Learners who prefer the accommodator style like to work in teams to complete their targets and actively work in the field trying different ways to achieve their goals. Accommodators prefer 'action-oriented' jobs such as nursing, teaching, marketing or sales. This is supported by the findings of Smith who reported that 217 registered nurses enrolled in online courses at a university favoured the accommodator style of learning ${ }^{[18]}$. The other two learning styles, Assimilator (22.8\%) and Converger (19.2\%), also had a significant presence, further reinforcing that educators should attempt to cater for all learning styles, instead of focusing on a single learning style.

Ideally, educators of undergraduate paramedic students should attempt to introduce a variety of different teaching approaches and methods strategies in order to enable learning to occur for all undergraduate paramedic students regardless of their learning style accommodate all learning styles of undergraduate paramedic students, and not just those of a particular learning style such as Diverger or Accommodator. While this appears to be logical, unfortunately very few studies have addressed this specifically. Therefore, these pilot study results provide some data in the learning styles and teaching styles discourse, and add to further add to the emerging body of paramedic knowledge.

The findings in this present study are similar to King ${ }^{[9]}$, who reported that a group of 79 nursing students were either Accommodators or Divergers. This is consistent with Kolb's belief that individuals associated with human-related profession are more likely to adopt concrete learning styles and are person orientated ${ }^{[5]}$. However in a study conducted over three years by Rakoczy and Money ${ }^{[19]}$ it was shown that nursing students preferred the Assimilator learning style. The findings in this study are similar to those obtained by Hauer et al ${ }^{[8]}$ who assessed the learning styles of 89 students enrolled in five health science curricula: nursing, physician's assistant, occupational therapist, physical therapist, and speech-language pathologist. Hauer and colleagues found that there was a close balance of learning style preferences between all four of Kolb's learning preferences, with none of the preferences being dominant. Similar to the findings of the present study, Hauer and colleagues reported that nursing students tended to prefer the Diverger learning style ${ }^{[8]}$. However the preference of Diverger was not the outright dominate learning style preference of nursing students learning style preferences, similar to the results found in our research with the accommodator preference also being preferred by undergraduate paramedic students. In a similar finding to King and Hauer, Smith revealed that 217 registered nurses enrolled in online courses at a university preferred the accommodator learning style ${ }^{[18]}$. Also, in a study performed by Zoghi, et al ${ }^{[1]}$, there were findings that indicated that undergraduate nursing and paramedic students preferred the Accommodator style of learning ${ }^{[1]}$. Once again, this is consistent with Kolb’s theory that individuals who are involved in human-related professions are more likely to prefer the Accommodator learning style.

The relatively even spread of the four learning styles amongst undergraduate paramedic students in this study suggests that learning styles are multidimensional. In other words, students can have the capacity to adjust their learning styles to suit 
the learning situation and educators can attempt to accommodate the varying learning styles of undergraduate paramedic students. We speculate that the learning style needs of paramedic students attending a lecture at university are different compared to online learning or when they are completing practical education placements, so having a degree of flexibility in their learning styles would be advantageous. Again this is important for the paramedic discipline as it attempts to acclimatise itself to the expectations of Higher Education. As was previously mentioned, according to Kolb's Learning Styles and Experimental Learning Model ${ }^{[5]}$, learning styles are not a fixed personality trait, but are instead viewed as patterns of behaviour based upon an individual's previous life experiences, education values and previously played roles.

\section{Study limitations}

There are a number of limitations to this study. The generalisability of these results is limited since the study was conducted at a single an Australian-based university using convenience sampling. Generalisability is also limited in other countries that have different educational programs, systems and qualification levels. Those students who self-select themselves to participate in this study may be of a particular type and thus it is possible that this sample is not representative of undergraduate paramedic students. The response rate was low which led to a small study size; however a response rate of $33.5 \%$ was achieved, which was deemed acceptable for self-report surveys, and pilot studies.

\section{Future research}

It is recommended that this study be replicated with a larger sample of paramedic students. For example, paramedic students from other universities could be recruited to increase the sample size. It is suggested that the relationships between learning styles, teaching styles and academic outcomes of students be investigated. The type of learning styles required in the academic classroom context and the 'on-road' practice practical education environment could be compared. Finally, investigating whether a student's learning style is predictive of their future academic performance is also potentially warranted.

\section{Conclusion}

A group of 57 students enrolled in an undergraduate paramedic course completed the K-LSI. This is the first time that we are aware of that the K-LSI has been applied to undergraduate paramedic students and yielded an interesting insight into the learning styles of undergraduate paramedic students. The results indicated that there was a spread of preferences among all four learning styles (Diverger, Accommodator, Assimilator and Converger); however, there was some preference shown towards the Diverger and Accommodator learning styles. Based on the spread of different learning style preferences amongst undergraduate paramedic students from a single university and literature available, it is recommended that educators take into consideration all the varying learning styles. Especially when planning, implementing and evaluating curriculum in order to create an optimal learning environment for their students.

\section{Acknowledgement}

The undergraduate paramedic students from the Bachelor of Emergency Health who volunteered their time to complete the study questionnaire are thanked. Their views and input were invaluable.

\section{References}

[1] Zoghi M, Brown T, Williams B, Roller L, Jaberzadeh S, Palermo C, et al. Learning style preferences of Australian health science students. Journal of Allied Health. 2010; 39(2): 95-103. PMid:20539932

[2] Mackway-Jones K, Carley S, Kilroy D. Advanced training in emergency medicine: a pedagogical journey from didactic teachers to virtual problems. Emergency Medicine Journal. 2007; 24(10): 696-8. PMid:17901268 http://dx.doi.org/10.1136/emj.2006.043885 
[3] Cook DA, Smith AJ. Validity of index of learning styles scores: multitrait-multimethod comparison with three cognitive/learning style instruments. Medical Education. 2006; 40(9): 900-7. PMid:16925641 http://dx.doi.org/10.1111/j.1365-2929.2006.02542.x

[4] Kolb D. The Kolb Learning Style Inventory Version 3. Boston: MA: Hay Resources Direct. 1999.

[5] Kolb D. Learning Style Inventory (revised edition). Boston: MA: McBer \& Company. 1985.

[6] Loo R. Kolb's Learning Styles and Learning Preferences: Is There a Linkage? Educational Psychology. 2004; 24(1).

[7] Bowman K, Delargy L, Deshong L, Kutcher R, Roush S. Learning styles of physical therapy students and clinicians. Physical Therapy. 2000; 80(5).

[8] Hauer P, Straub C, Wolf S. Learning styles of allied health students using Kolb's LSI-IIa. Journal of Allied Health. 2005; 34(3): 177-82. PMid:16252681

[9] King JE. A comparative study of adult developmental patterns of RN and generic students in a baccalaureate nursing program. Journal of Nursing Education. 1986; 25(9): 366-71. PMid:3023577

[10] Linares AZ. Learning styles of students and faculty in selected health care professions. Journal of Nursing Education. 1999; 38(9): 407-14. PMid:10609585

[11] Cavanagh SJ, Hogan K, Ramgopal T. The assessment of student nurse learning styles using the Kolb Learning Styles Inventory. Nurse Education Today. 1995; 15(3): 177-83. http://dx.doi.org/10.1016/S0260-6917(95)80103-0

[12] Roberts K, Taylor B. Nursing Research Processes: An Australian Perspective. Melbourne: Nelson Australia. 1998.

[13] Payton O, Heuter A. Learning style preferences: Physical therapy students in the United States. Physical Therapy. $1979 ; 59$.

[14] Huston J, Cohen T. How learning style and personality type can affect performance. Health Care Supervision. 1995 ; 13. PMid:10184342

[15] Kolb D. Learning Style Inventory. Boston, MA: McBer \& Company. 1993.

[16] Veres I, Sims R, Locklear T. Improving the reliability of Kolb’s Revised Learning Style Inventory. Educational and Psychological Measurement. 1991; 51: 143-50. http://dx.doi.org/10.1177/0013164491511013

[17] Kirkpatrick L, Feeney B. A simple guide to SPSS for Windows: For versions 8.0, 9.0, and 10.0 (revised edition). Belmont, CA: Wadsworth. 2001.

[18] Smith A. Learning styles of registered nurses enrolled in an online nursing program. Journal of Professional Nursing. 2010; 26(1): 49-53. PMid:20129593 http://dx.doi.org/10.1016/j.profnurs.2009.04.006

[19] Rakoczy M, Money S. Learning styles of nursing students: a 3-year cohort longitudinal study. Journal of Professional Nursing. 1995; 11(3): 170-4. http://dx.doi.org/10.1016/S8755-7223(95)80116-2 